\title{
Poluição atmosférica
}

\section{ALFESIO BRAGA \\ Q LUIZ ALBERTO \\ AMADOR PEREIRA}

são doutores e

pesquisadores do

Departamento de

Patologia da Faculdade de

Medicina da USP.

\section{GYÖRGY MIKLÓS}

BÖHM e PAULO

SALDIVA são professores

titulares do Departamento de Patologia da Faculdade de Medicina da USP.

\section{e saúde humana}

ALFESIO BRAGA

GYÖRGY MIKLÓS BÖHM

LUIZ ALBERTO AMADOR PEREIRA

PAULO SALDIVA

\section{INTRODUÇÃO}

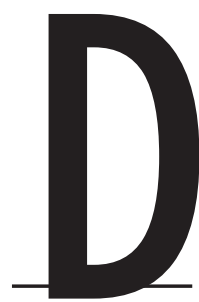

esde que surgiram seus primeiros ancestrais na superfície da Terra, há aproximadamente um milhão de anos, na porção mais ao sul do continente africano, o homem tem atuado de forma transformadora e, muitas vezes, predatória sobre a natureza. A partir da descoberta do fogo, aproximadamente 800 mil anos antes de Cristo, o homem passou a contribuir de forma atuante, porém não consciente, para a deterioração da qualidade do ar e a sofrer as conseqüências desse ato.

Olhando esta trajetória, presunçosamente, como um adulto que analisa sua infância e adolescência, pode-se até entender a imaturidade o desconhecimento, a presunção e a irresponsabilidade com que a humanidade trilhou seus caminhos durante os séculos preocupando-se somente em extrair do planeta tudo o que desejasse, como se a fonte fosse inesgotável. Nesse contexto enquadram-se as destruições de grandes reservas florestais em todos os continentes para extração de madeiras, para a instalação de gran- 
des áreas de agricultura, pecuária e também de cidades. A caça predatória traduziu-se na extinção ou quase extinção de um grande número de animais em todo o planeta.

No último século tem-se assistido ao apogeu da intervenção do homem sobre o planeta, com o surgimento dos motores a combustão, com a queima de combustíveis fósseis, com o surgimento das indústrias siderúrgicas e de produtos químicos. Esses processos não foram acompanhados de análises que pudessem avaliar seu impacto sobre o meio ambiente, a toxicidade dos resíduos produzidos ou os prováveis danos à saúde. Por isso, nos últimos setenta anos, temos nos deparado com os resultados desastrosos desse processo desordenado e lutado para entender o que são os resíduos dessa corrida desenvolvimentista e evitar seus efeitos deletérios para o planeta e seus habitantes.

Um dos elementos que mais têm sido agredidos pelo homem é o ar. Indispensável para a vida, uma vez que não se pode deixar de respirar, provavelmente não recebeu maiores atenções pelo fato de ser abundante, invisível e inodoro. Porém, ao longo da história do progresso da humanidade, suas características foram mudando.

As primeiras preocupações com a qualidade do ar apareceram na era pré-cristã. Devido ao uso do carvão como combustível, as cidades dessa época já ostentavam ares de qualidade aquém do desejável. Essa situação veio se agravando durante os primeiros séculos da história pós-cristã, quando os primeiros atos de controle de emissão de fumaça foram baixados na Inglaterra do final do século XIII, passando pela Revolução Industrial e pelo crescimento das cidades.

A poluição do ar tem sido, desde a primeira metade do século $X X$, um grave problema nos centros urbanos industrializados, com a presença cada vez maior dos automóveis, que vieram a somar com as indústrias, como fontes poluidoras. 
Episódios de poluição excessiva causaram aumento do número de mortes em algumas cidades da Europa e Estados Unidos. O primeiro episódio ocorreu em 1930 , no Vale de Meuse, Bélgica, entre as cidades de Huy e Liége, uma região com grande concentração de indústrias, sendo quatro siderúrgicas, três metalúrgicas, quatro centrais de produção de energia elétrica e suas minas de carvão, seis indústrias de cerâmica e vidro que utilizavam fornos a carvão ou gasogênio, três indústrias de cimento, três indústrias de transformação química de minerais, uma carvoaria, uma fábrica de pólvora, uma fábrica de ácido sulfúrico e uma fábrica de adubos, distribuídas em uma faixa de aproximadamente vinte quilômetros de comprimento. Nos cinco primeiros dias do mês de dezembro, condições meteorológicas desfavoráveis, como a ausência de ventos, impediram a dispersão dos poluentes, que permaneceram estacionados sobre a região. Imediatamente foi registrado um aumento do número de doenças respiratórias e um excesso de mortes (60 mortes) até dois dias após o início do episódio.

Alguns anos após, um episódio semelhante ocorreu durante os últimos cinco dias do mês de outubro de 1948 na cidade de Donora, Pensilvânia. Os produtos da combustão das indústrias locais permaneceram sobre a cidade devido à ocorrência de inversões térmicas que impediram a dispersão desses poluentes. Inversão térmica é um fenômeno meteorológico em que ocorre a presença de uma camada de ar frio alguns metros acima da superfície que impede a dispersão e a movimentação de massas de ar mais quentes localizadas próximas do solo. Essa camada mais fria age como se fosse a tampa de uma panela concentrando vapor no seu interior. Durante esse período foram observadas 20 mortes ao invés das duas mortes esperadas normalmente em uma comunidade de 14.000 pessoas.

Porém, o mais clássico e mais grave dos episódios acerca dos efeitos deletérios dos poluentes do ar foi o acontecido em Londres. Durante o inverno de 1952, um episódio de inversão térmica impediu a disper- são de poluentes gerados então pelas indústrias e pelos aquecedores domiciliares que utilizavam carvão como combustível, e uma nuvem, composta principalmente por material particulado e enxofre (em concentrações até nove vezes maiores do que a média de ambos), permaneceu estacionada sobre a cidade por aproximadamente três dias, levando a um aumento de quatro mil mortes em relação à média de óbitos em períodos semelhantes.

Indiscutivelmente, esses trágicos episódios direcionaram os olhos dos pesquisadores para a necessidade de se buscar o controle da emissão de poluentes do ar.

Em 1955, o Congresso norte-americano liberou cinco milhões de dólares para a realização de estudos sobre o impacto da poluição atmosférica sobre a saúde e a economia. Ações de controle ambiental não eram a pauta de discussão até aquele momento. Só a partir do início da década de 60 , foi criado um programa federal de poluição atmosférica, ligado ao Departamento de Saúde, Educação e Bem-Estar Social dos Estados Unidos. Esse programa delegou a responsabilidade do controle da emissão dos diversos poluentes atmosféricos aos estados da Federação, ficando a cargo do governo federal somente o estabelecimento das diretrizes necessárias para efetuar e viabilizar esse controle. Contudo, tal medida mostrou-se ineficaz já que vários estados não estavam preparados e estruturados para a realização dessas ações controladoras. Novos episódios de aumento súbito da poluição ocorreram, um deles em Nova York, durante quatro dias de novembro de 1966, onde foram necessárias oito mortes e forte pressão da mídia para que se decretasse estado de emergência.

Diante desses novos episódios, ainda na década de 60, os Estados Unidos estabeleceram padrões de qualidade do ar, especificando os seis poluentes atmosféricos que seriam controlados: partículas totais, dióxido de enxofre $\left(\mathrm{SO}_{2}\right)$, monóxido de carbono $(\mathrm{CO})$, dióxido de nitrogênio $\left(\mathrm{NO}_{2}\right)$, ozônio $\left(\mathrm{O}_{3}\right)$ e chumbo $(\mathrm{Pb})$. A fim de efetivar esse controle, criou-se a Agência de Proteção Ambiental norte-americana 
(EPA). Várias medidas de controle foram, então, implantadas, visando não só atingir as fontes de emissão móveis, como também as estacionárias. Em 1990, foram conferidos à EPA poderes para determinar os critérios técnicos de controle das substâncias tóxicas, com base nos seus efeitos à saúde. Vários estudos epidemiológicos e experimentais contribuíram consideravelmente para a implantação desses controles, bem como para a elaboração de manuais de orientação. Porém, ainda que aprimoradas ao longo dos anos, tais medidas de controle não foram suficientes. Em 1991, aproximadamente 87 milhões de pessoas nos Estados Unidos permaneciam expostas a níveis superiores aos padrões de qualidade do ar estabelecidos pela legislação norteamericana (Tabela 1).

Na Europa, o desenvolvimento de ações controladoras também foi bastante influenciado pelo episódio ocorrido em 1952 na cidade de Londres. O Parlamento inglês, em 1956, atribuiu às autoridades locais o controle das áreas de maior risco da ocorrência de acúmulo de fumaça preta emitida pelas chaminés das residências, obrigando a troca do sistema a carvão por eletricidade, gás ou óleo diesel. Para tanto, o governo forneceu os subsídios necessários para a mudança dos sistemas de calefação para esses tipos de combustível.

Os Clean Air Acts de 1956 e 1968 também ampliaram os controles de emissão de poluentes atmosféricos industriais, regulamentando as emissões de óxidos de enxofre e fumaça preta. Houve uma grande resistência por parte do setor industrial em cumprir as metas de adequação e diminuição da quantidade de emissão desses poluentes.

O fato é que, ao longo dos anos, as concentrações dos poluentes foram decrescendo nas grandes cidades inglesas, parte em função de um controle social mais efetivo, mas também em decorrência do ingresso da Inglaterra no Mercado Comum Europeu.

A Comunidade Européia, já no início dos anos 70, demonstrou, através de propostas e discussões de medidas de controle, estar suficientemente convencida da existência de danos à saúde causados pelas altas concentrações de poluentes atmosféricos. Esse fator foi fundamental para que a Inglaterra, com a sua inserção junto à Comunidade Européia em 1973, fosse obrigada a adequar-se à legislação no que tange ao controle ambiental.

Em 1976, uma comissão de países europeus (Comission of the European Communities - CEC) estabeleceu padrões de qualidade do ar para $\mathrm{SO}_{2}, \mathrm{CO}, \mathrm{NO}_{2}$, ma-

TABELA I

\section{Padrões de qualidade do ar para os principais poluentes segundo a Environmental Protection Agency (EPA) dos Estados Unidos}

\begin{tabular}{lll}
\hline Poluentes & Padrões primários & Tempo médio \\
\hline Partículas inaláveis & $50 \mu \mathrm{g} / \mathrm{m}^{3}$ & Média aritmética anual \\
\hline$\left(\mathrm{PM}_{10}\right)$ & $150 \mu \mathrm{g} / \mathrm{m}^{3}$ & Nível limite para 24 horas \\
\hline Ozônio $\left(\mathrm{O}_{3}\right)$ & $0,12 \mathrm{ppm}\left(235 \mu \mathrm{g} / \mathrm{m}^{3}\right)$ & Média de I hora máxima diária \\
\hline Dióxido de enxofre $\left(\mathrm{SO}_{2}\right)$ & $0,03 \mathrm{ppm}\left(80 \mu \mathrm{g} / \mathrm{m}^{3}\right)$ & Média aritmética anual \\
\hline Monóxido de carbono $(\mathrm{CO})$ & $9 \mathrm{ppm}\left(10 \mu \mathrm{g} / \mathrm{m}^{3}\right)$ & Nível máximo em 24 horas \\
\hline Dióxido de nitrogênio $\left(\mathrm{NO}_{2}\right)$ & $0,053 \mathrm{ppm}\left(100 \mu \mathrm{gg} / \mathrm{m}^{3}\right)$ & Média máxima de 8 horas \\
\hline
\end{tabular}

Fonte: Bascon e cols., "Health Effects of Outdoor Air Pollution", in Am. J. Crit. Care Med. I 53, 1996, pp. 3-50. 
terial particuladoe oxidantes fotoquímicos. Esses padrões foram sendo aprimorados ao longo dos anos, subsidiando as legislações dos diversos países europeus de uma maneira uniforme.

À medida que os países desenvolvidos foram aperfeiçoando formas de controle ambiental, várias indústrias passaram a migrar para países onde a legislação e o controle fossem mais amenos ou mesmo inexistentes. Entre as décadas de 60 e 70, inúmeros países periféricos economicamente, ávidos por novas fontes de recursos e desenvolvimento, receberam indústrias multinacionais de produtos de base, principalmente na área petroquímica. Muitas dessas indústrias tinham como sede países onde a legislação ambiental determinava a realização de altos investimentos em tecnologia, principalmente para a prevenção de possíveis acidentes ambientais.

Contudo, outros episódios envolvendo o aumento das concentrações de poluentes atmosféricos continuaram a ocorrer, mas dessa vez nos países em desenvolvimento.

Bhopal, na Índia, ilustra um desses episódios, talvez o mais dramático, ocorrido na década de 80. Na noite de 3 de dezembro de 1984, um grande vazamento de methilisocianato (MIC) proveniente da Union Carbide, indústria localizada próxima à cidade, causou a morte de, pelo menos, 1.700 pessoas devido a um intenso edema pulmonar (acúmulo de líquido no pulmão) causado pela reação exotérmica do MIC com a água do tecido pulmonar. Além das mortes, milhares de pessoas ficaram com seqüelas graves, como o comprometimento irreversível da função do pulmão.

Ao longo do século passado ocorreram outros desastres ambientais, não obstante todos os conhecimentos acumulados acerca dos prejuízos e altos custos sociais. Mesmo nos países desenvolvidos, onde o controle ambiental é mais efetivo, existe uma contínua discussão crítica sobre os efeitos da poluição atmosférica, mesmo naquelas concentrações consideradas "seguras" pela legislação. Observa-se, também, que o rápido crescimento urbano nos países em desenvolvimento fez com que as fontes móveis ou veiculares se tornassem um problema de grande magnitude, devido ao número e estado de conservação desses veículos, muitas vezes sem o controle necessário quanto à qualidade do combustível, dos motores e mecanismos de filtragem dos gases emitidos pelos mesmos.

Há nos países desenvolvidos uma preocupação crescente com o aprimoramento de estudos usando os mais variados modelos e tendo como meta elucidar todo e qualquer questionamento. Vale ressaltar que, em tais países, o número de estudos sobre poluição atmosférica e seus efeitos deletérios à saúde tem crescido vertiginosamente ao longo das últimas décadas. O conhecimento científico adquirido tem influenciando e muito nas políticas públicas de controle ambiental nesses países.

\section{PRINCIPAIS POLUENTES ATMOSFÉRICOS}

\section{Material particulado}

O material particulado é uma mistura de partículas líquidas e sólidas em suspensão no ar. Sua composição e tamanho dependem das fontes de emissão. O tamanho das partículas é expresso em relação ao seu tamanho aerodinâmico, definido como o diâmetro de uma esfera densa que tem a mesma velocidade de sedimentação que a partícula em questão. Em geral, as partículas podem ser divididas em dois grupos:

- partículas grandes, com diâmetro entre 2,5 e $30 \mu \mathrm{m}$ de diâmetro, também chamadas "tipo grosseiro" (coarse mode), de combustões descontroladas, dispersão mecânica do solo ou outros materiais da crosta terrestre, que apresentam características básicas, contendo silício, titânio, alumínio, ferro, sódio e cloro. Pólens e esporos, materiais biológicos, também se encontram nesta faixa;

- partículas derivadas da combustão de fontes móveis e estacionárias, como auto- 
móveis, incineradores e termoelétricas, em geral, são de menor tamanho, apresentando diâmetro menor que 2,5 $\mu \mathrm{m}$ (fine mode), e têm maior acidez, podendo atingir as porções mais inferiores do trato respiratório, prejudicando as trocas gasosas. Entre seus principais componentes temos carbono, chumbo, vanádio, bromo e os óxidos de enxofre e nitrogênio, que na forma de aerossóis (uma estável mistura de partículas suspensas em um gás) são a maior fração das partículas finas.

Éoportuno salientar que a determinação da EPA para controle de partículas menores ou iguais a $10 \mu \mathrm{m}\left(\mathrm{PM}_{10}\right)$, também chamadas de partículas inaláveis, baseou-se no fato de que estas são as partículas que podem atingir as vias respiratórias inferiores, e não na sua composição química. Esse material particulado inalável apresenta uma característica importante que é a de transportar gases adsorvidos em sua superfície até as porções mais distais das vias aéreas, onde ocorrem as trocas de gases no pulmão.

Fumaça Britânica (BS) é um padrão de material particulado, utilizado nos estudos realizados na Grã-Bretanha e outros países europeus, cuja estimativa da massa é baseada em um padrão de reflexão, com partículas finas sendo mais escuras. É aceito pela EPA, como uma fração entre PM $_{10}$ e TPS (partículas totais em suspensão, com limite superior de $100 \mu \mathrm{m})$.

Estudo realizado com monitores pessoais para $\mathrm{PM}_{10}$ e monitores colocados dos lados externo e interno das residências mapeou a composição do particulado domiciliar. Aproximadamente $50 \%$ do particulado no interior das casas é proveniente do ambiente externo. O restante tem origem no fumo, fogão a gás e de origem indeterminada.

À medida que vão se depositando no trato respiratório, essas partículas passam a ser removidas por alguns mecanismos de defesa. O primeiro deles é o espirro, desencadeado por grandes partículas que, devido ao seu tamanho, não conseguem ir além das narinas, onde acabam se depositando. A tosse é um mecanismo semelhante que acontece quando há a invasão do trato res- piratório inferior (além da laringe) por partículas. Quando as partículas se depositam na superfície das células do trato respiratório, um outro mecanismo de defesa entra em funcionamento: o aparelho muco-ciliar. Fazem parte da superfície do aparelho respiratório células com cílios e células secretoras de muco. Os cílios permanecem constantemente em movimento, no sentido do pulmão para a boca, empurrando o muco para fora do trato respiratório. As partículas que se depositam sobre o muco também são carregadas. Um fato muito comum nos dias atuais pode servir como exemplo prático desse mecanismo. Quando um jovem ("partícula") sobe num palco de um espetáculo de rock e se joga sobre a platéia (células do aparelho muco-ciliar) ele é carregado pela platéia por alguns metros (os braços representam o papel dos cílios que fazem esse movimento em apenas um sentido). As partículas que chegam à orofaringe podem ser deglutidas. Aquelas partículas que atingem as porções mais distais das vias aéreas são fagocitadas (englobadas) pelos macrófagos alveolares, sendo então removidas via aparelho mucociliar ou sistema linfático.

\section{Ozônio $\left(0_{3}\right)$}

O ozônio presente na troposfera, a porção da atmosfera em contato com a crosta terrestre, é formado por uma série de reações catalisadas pela luz do sol (raios ultravioleta) envolvendo, como precursores, óxidos de nitrogênio $\left(\mathrm{NO}_{\mathrm{x}}\right)$ e hidrocarbonetos, derivados de fontes de combustão móveis, como os veículos automotivos, de fontes estacionárias, como usinas termoelétricas, e até mesmo fontes naturais como as árvores, que contribuem na produção de compostos orgânicos voláteis.

Os níveis de ozônio aumentam consideravelmente entre o fim da primavera e o começo do outono, em regiões periféricas de grandes centros urbanos, localizadas nas direções em que sopram os ventos. Caracteristicamente, seus níveis de concentra- 
ção aumentam no meio da manhã, algumas horas após o rush matinal do trânsito (nível máximo de emissão de óxidos de nitrogênio), atingindo seu ápice no meio da tarde e declinando à noite.

As concentrações de ozônio nos ambientes externos são maiores que nos interiores dos edifícios, porém esta diferença pode diminuir dependendo do tipo de ventilação do local analisado. Como fonte domiciliar de ozônio podem ser citados os purificadores de ar, enquanto as máquinas de fotocópias são fontes de ozônio nos escritórios e estabelecimentos comerciais.

O ozônio é um potente oxidante, citotóxico (provoca lesão das células), que atinge as porções mais distais das vias aéreas.

\section{Dióxido de enxofre $\left(\mathrm{SO}_{2}\right)$}

\section{e aerossóis ácidos}

Resultado da combustão de elementos fósseis, como carvão e petróleo, têm como fontes principais os automóveis e termoelétricas. Uma vez lançado na atmosfera, $\mathrm{O} \mathrm{SO}_{2}$ é oxidado, formando ácido sulfúrico $\left(\mathrm{H}_{2} \mathrm{SO}_{4}\right)$. Essa transformação depende do tempo de permanência no ar, da presença de luz solar, temperatura, umidade e adsorção do gás na superfície das partículas. A permanência no ar por um período grande de tempo faz com que o $\mathrm{SO}_{2}$ e seus derivados (aerossóis ácidos) sejam transportados para regiões distantes das fontes primárias de emissão, aumentando a área de atuação desses poluentes.

$\mathrm{O} \mathrm{SO}_{2}$ é altamente solúvel em água a $30^{\circ} \mathrm{C}$. A maior parte do $\mathrm{SO}_{2}$ inalado por uma pessoa em repouso é absorvida nas vias aéreas superiores. A atividade física leva a um aumento da ventilação, com consequiente aumento da absorção nas regiões mais distais do pulmão. Sua eliminação se faz, basicamente, pela expiração e pela urina, com a eliminação de dois metabólitos, o sulfato e o éster sulfato.

Dissolvidos nas gotas de água presentes na atmosfera, encontramos os aerossóis ácidos mais comuns: sulfato $\left(\mathrm{SO}_{4}{ }^{--}\right)$e bissulfato $\left(\mathrm{HSO}_{4}^{-}\right)$. $\mathrm{O}$ ácido sulfúrico $\left(\mathrm{H}_{2} \mathrm{SO}_{4}\right)$ é o aerossol ácido mais irritante para o trato respiratório, apresentando $\mathrm{pH}$ menor que um. O ácido sulfúrico e seus sais de amônia constituem a maior parte das partículas finas.

\section{Monóxido de carbono (CO)}

Com exceção dos fumantes, que possuem suas próprias fontes emissoras de CO, todos os demais habitantes dos grandes centros urbanos recebem sua cota de CO do trânsito intenso, pois os automóveis são as maiores fontes de emissão desse poluente. Pessoas que passam várias horas do dia dentro de um automóvel ou que tenham que andar a pé ou de bicicleta são os mais afetados. Porém os ambientes internos, como residências e escritórios, podem vir a sofrer os efeitos do CO proveniente do ambiente externo que entra pelo sistema de ventilação, ou que é produzido localmente por aquecedores a óleo, fumantes, churrasqueiras e fogão a gás.

A determinação dos níveis de carboxihemoglobina no sangue pode servir para avaliar a exposição individual, uma vez que pessoas saudáveis e não-fumantes, residentes em áreas de grande concentração ambiental de CO, apresentam um aumento de até $100 \%$ nos níveis de carboxihemoglobina quando comparados aos de pessoas saudáveis e não-fumantes que não estão expostas aos níveis de CO dos grandes centros urbanos.

O monóxido de carbono apresenta afinidade pela hemoglobina 240 vezes maior que a do oxigênio, o que faz com que uma pequena quantidade de $\mathrm{CO}$ possa saturar uma grande quantidade de moléculas de hemoglobina, diminuindo a capacidade do sangue de transportar $\mathrm{O}_{2}$. Outro efeito devido ao CO é o desvio da curva de dissociação da hemoglobina para a esquerda levando à diminuição da liberação de $\mathrm{O}_{2}$ nos tecidos. 


\section{Óxidos de nitrogênio $\left(\mathrm{NO}_{\mathrm{x}}\right)$}

As principais fontes de óxido nítrico (NO) e dióxido de nitrogênio $\left(\mathrm{NO}_{2}\right)$ são os motores dos automóveis. As usinas termoelétricas e indústrias que utilizam combustíveis fósseis contribuem em menor escala. Durante a combustão sob elevadas temperaturas, o oxigênio reage com o nitrogênio formando óxido nítrico (NO), dióxido de nitrogênio $\left(\mathrm{NO}_{2}\right)$ e outros óxidos de nitrogênio $\left(\mathrm{NO}_{\mathrm{x}}\right)$. Esses compostos são extremamente reativos e na presença de oxigênio $\left(\mathrm{O}_{2}\right)$, ozônio e hidrocarbonetos, o NO se transforma em $\mathrm{NO}_{2}$. Por sua vez, $\mathrm{NO}_{2}$ na presença de luz do sol reage com hidrocarbonetos e oxigênio formando ozônio $\left(\mathrm{O}_{3}\right)$, sendo um dos principais precursores desse poluente na troposfera.

Ao contrário de outros poluentes gasosos, as concentrações de $\mathrm{NO}_{2}$ nos ambientes internos estão intimamente relacionadas com as concentrações externas, uma vez que este poluente se difunde com muita facilidade de fora para dentro das edificações através de mecanismos de ventilação. A isto se soma o fato de existirem várias fontes de $\mathrm{NO}_{2}$ e outros óxidos de nitrogênio $\left(\mathrm{NO}_{\mathrm{x}}\right)$ dentro das residências, como fogões a gás, aquecedores que utilizam querosene (mais freqüentes em regiões frias) e o cigarro.

$\mathrm{O} \mathrm{NO}_{2}$, quando inalado, atinge as porções mais periféricas do pulmão devido à sua baixa solubilidade. Seu efeito tóxico está relacionado ao fato de ser um agente oxidante.

\section{PRINCIPAIS EVIDÊNCIAS DOS EFEITOS DA POLUIČÃO DO AR SOBRE A SAÚDE HUMANA}

A convivência dos seres vivos, em especial a do homem, com a poluição do ar tem trazido consequiências sérias para a saúde. Os efeitos dessa exposição têm sido marcantes e plurais quanto à abrangência.
Em países desenvolvidos e em desenvolvimento, crianças, adultos e idosos, previamente doentes ou não, sofreram e ainda sofrem seus malefícios, como citado anteriormente. As principais fontes poluidoras, que são os veículos automotivos e as indústrias, estão presentes em todos os grandes centros urbanos. Nas últimas três décadas, o melhor conhecimento das origens, composições, comportamentos, interações e, do ponto fulcral, os mecanismos de ação desses verdadeiros inimigos da saúde pública têm mobilizado esforços e recursos tecnológicos e financeiros diversos.

Estudos observacionais têm procurado mostrar, com resultados cada vez mais significativos, efeitos de morbidade e mortalidade associados aos poluentes do ar. No entanto, para se avaliar a plausibilidade biológica desses achados, tem sido necessária a realização de estudos de intervenção e experimentais.

O aprimoramento de técnicas de análise estatística de séries temporais, o tipo de estudo ecológico predominante quando se analisa mortalidade e sua associação com poluentes conferem confiabilidade aos resultados.

Esses novos conhecimentos têm alteradoconceitos previamente existentes. A adoção dos critérios de qualidade do ar foi baseada em conhecimentos existentes até aquele momento. Contudo, estudos mais recentes mostram que podemos encontrar efeitos graves sobre a saúde mesmo quando os poluentes se encontram dentro dos padrões de segurança.

Assim como mortalidade pode ser um marcador de efeitos sobre a saúde, parâmetros de morbidade também podem sê-lo, visto que pessoas levadas à morte devem ter apresentado toda uma história de alterações clínicas anteriormente. Essas alterações clínicas têm sido documentadas na forma de exacerbações de sintomas respiratórios e cardiovasculares, aumento das crises de asma e dor pré-cordial, limitação funcional, maior utilização de medicamentos, número de consultas em pronto-socorro e internações hospitalares.

Em síntese, através da análise dos estu- 
dos realizados em diversos centros urbanos, que utilizaram estes e outros desenhos epidemiológicos, pode-se concluir que:

- as concentrações de poluentes atmosféricos encontradas em grandes cidades acarretam afecções agudas e crônicas no trato respiratório, mesmo em concentrações abaixo do padrão de qualidade do ar. A maior incidência de patologias, tais como asma e bronquite, está associada com as variações das concentrações de vários poluentes atmosféricos;

- a mortalidade por patologias do sistema respiratório apresenta uma forte associação com a poluição atmosférica;

- as populações mais vulneráveis são as crianças, idosos e aquelas que apresentam doenças respiratórias;

- material particulado inalável, com dimensão inferior a $10 \mu \mathrm{m}$ e mais recentemente $2,5 \mu \mathrm{m}$, é apontado como o poluente mais freqüentemente relacionado com danos à saúde;

- sinais, cada vez mais evidentes, mostram que os padrões de qualidade do ar são inadequados para a proteção da população mais suscetível à poluição atmosférica. Vários estudos demonstraram ocorrência de efeitos mórbidos em concentrações abaixo dos padrões de qualidade do ar;

- a mortalidade por doenças cardiovasculares também tem sido relacionada à poluição atmosférica urbana, sendo novamente o material particulado inalável o poluente frequientemente associado;

- estudos experimentais e toxicológicos têm dado sustentação aos resultados encontrados em estudos epidemiológicos.

\section{FONTES DE POLUICĀOAO E CONTROLE DA QUALLADE DO AR EM SÃO PAULO}

São Paulo é uma das dez maiores cidades do mundo, com aproximadamente 16 milhões de habitantes na Região Metropolitana (RMSP). O clima na RMSP pode ser resumido como seco no inverno e úmido no verão. De setembro a abril, a área é dominada por vento úmido do sul e ocorrência de sistemas frontais, resultando em precipitações e nuvens de baixa altitude. Durante o inverno, formações de alta pressão no Oceano Atlântico ao leste dirigemse para o norte, produzindo ventos fracos provenientes da costa, fortes inversões térmicas de subsidiência e céu claro. Sua precipitação anual é de $1.900 \mathrm{~mm}$, com temperatura média que varia entre $15-22^{\circ} \mathrm{C}$.

As duas principais fontes de emissão de poluentes são as indústrias, atualmente localizadas na RMSP, e a frota de veículos automotores que circula pela cidade. Essa frota é responsável por grande parte da carga de poluentes emitidos na atmosfera, podendo ser estimada em mais de 4,3 milhões de veículos automotores.

A história do crescimento urbano de São Paulo tem sido marcada pela falta de priorização de transportes coletivos de qualidade. Vale lembrar que o metrô foi inaugurado somente em $1974 \mathrm{e}$, ainda hoje, atende a uma parcela pequena da população. Ao longo de décadas, o transporte individual foi se tornando uma opção natural, devido não só à insuficiência do transporte público, como também pelas facilidades de acesso e aquisição do automóvel. Conseqüentemente, a proporção do número de carros por habitante cresceu de $1 / 40$, na década de 40 , para quase $1 / 2$ nos anos 90 . Ocorre que, nesse período, a malha viária não acompanhou o mesmo crescimento.

Outra característica do crescimento da cidade é a mudança de várias indústrias do município de São Paulo para outros municípios. Ao longo dos anos, São Paulo foi se transformando em uma cidade predominantemente de serviços. Face a esse processo, a emissão de poluentes atmosféricos através de fontes móveis foi aumentando gradativamente, de forma bastante significativa. Pode-se dizer, aliás, que as fontes móveis são responsáveis por $90 \%$ da emissão de poluentes na cidade.

As primeiras iniciativas para monitorar a qualidade do ar ocorreram na RMSP e datam do início dos anos 60. Por iniciativa dos municípios de Santo André, São Bernardo do Campo, São Caetano do Sul e 
Mauá, em 16 de agosto de 1960 foi firmado um convênio para o controle da poluição das águas e do ar na região, através da Comissão Intermunicipal de Controle da Poluição das Águas e do Ar (CICPAA). Entre 1960 e 1971, desenvolveu-se trabalho pioneiro que contou com o apoio financeiro da Organização Pan-americana de Saúde (Opas).

Um convênio, firmado entre essas prefeituras e o estado de São Paulo, transferiu a CICPAA para a Superintendência de Saneamento Ambiental (Susam), órgão estadual criado em 17 de abril de 1970. Posteriormente, essas atribuições de controle da qualidade do ar e da água foram transferidas para a Companhia Estadual de Tecnologia de Saneamento Básico(Cetesb), inicialmente um centro de tecnologia em engenharia sanitária, fundado em 1968, que com o passar dos anos veio a assumir o controle de todas as atividades relacionadas ao controle da qualidade da água, do ar e do solo no estado de São Paulo.

A legislação federal estabelece, em relação ao controle de poluentes, dois padrões de qualidade do ar:

- padrões primários de qualidade do ar: são as concentrações de poluentes que, quando ultrapassadas, poderão acarretar danos à saúde da população;

- padrões secundários de qualidade do ar: são as concentrações de poluentes abaixo das quais se espera o mínimo efeito sobre a saúde da população, da fauna e da flora.

Essa definição, que consta de portaria normativa do Instituto Brasileiro de Apoio ao Meio Ambiente (Ibama) de 14 de março de 1990, e que foi transformada em resolução pelo Conama (Conselho Nacional do Meio Ambiente) em 28 de junho de 1990 , define que, a curto e médio prazo, os padrões primários devem ser os desejados e que, a longo prazo, os padrões secundários devem ser objetivados.

A mesma resolução do Conama regulamentou os níveis dos seguintes poluentes: partículas totais em suspensão (partículas com menos de $100 \mu \mathrm{m}$ ), dióxido de enxofre, monóxido de carbono, ozônio, fumaça (fuligem) - medidas rotineiramente em outras regiões do estado de São Paulo, excluindose a região metropolitana e Cubatão -, partículas inaláveis e dióxido de nitrogênio.

Como pode sernotado, os padrões primários adotados pelo Conama são, em geral, os mesmos adotados pela EPA (Tabela 2).

Devido às suas características climáticas anteriormente citadas, São Paulo está sujeita, durante os meses mais frios, a episó-

TABELA 2

Padrões nacionais de qualidade do ar, segundo Resolução Conama no 3 de 28/6/90

\begin{tabular}{|c|c|c|c|}
\hline Poluente & $\begin{array}{l}\text { Tempo } \\
\text { de amostragem }\end{array}$ & $\begin{array}{l}\text { Padrão primário } \\
\left(\mu \mathrm{g} / \mathrm{m}^{3}\right)\end{array}$ & $\begin{array}{l}\text { Padrão secundário } \\
\left(\mu \mathrm{g} / \mathrm{m}^{3}\right)\end{array}$ \\
\hline $\begin{array}{l}\text { Partículas totais } \\
\text { em suspensão (PTS) }\end{array}$ & $\begin{array}{l}24 \text { horas }(1) \\
M G A(2)\end{array}$ & $\begin{array}{r}240 \\
80\end{array}$ & $\begin{array}{r}150 \\
60\end{array}$ \\
\hline $\begin{array}{l}\text { Dióxido de } \\
\text { enxofre }\end{array}$ & $\begin{array}{l}24 \text { horas } \\
\text { MAA(3) }\end{array}$ & $\begin{array}{r}365 \\
80\end{array}$ & $\begin{array}{r}100 \\
40\end{array}$ \\
\hline $\begin{array}{l}\text { Monóxido de } \\
\text { carbono }\end{array}$ & $\begin{array}{l}\text { I hora }(1) \\
8 \text { horas }\end{array}$ & $\begin{array}{l}40.000(35 \text { ppm) } \\
10.000 \text { (9 ppm) }\end{array}$ & $\begin{array}{l}40.000(35 \text { ppm) } \\
10.000 \text { (9 ppm) }\end{array}$ \\
\hline Ozônio & I hora(I) & 160 & 160 \\
\hline Fumaça & $\begin{array}{l}24 \text { horas }(1) \\
\operatorname{MAA}(3)\end{array}$ & $\begin{array}{r}150 \\
60 \\
\end{array}$ & $\begin{array}{r}100 \\
40 \\
\end{array}$ \\
\hline $\begin{array}{l}\text { Partículas } \\
\text { inaláveis }(\mathrm{Pl})\end{array}$ & $\begin{array}{l}24 \text { horas }(1) \\
\operatorname{MAA}(3)\end{array}$ & $\begin{array}{r}150 \\
50\end{array}$ & $\begin{array}{r}150 \\
50\end{array}$ \\
\hline $\begin{array}{l}\text { Dióxido } \\
\text { de nitrogênio }\end{array}$ & $\begin{array}{l}\text { I hora(I) } \\
\operatorname{MAA}(3)\end{array}$ & $\begin{array}{l}320 \\
100\end{array}$ & $\begin{array}{l}190 \\
100\end{array}$ \\
\hline
\end{tabular}

I - Não deve ser ultrapassado mais que uma vez ao ano

2 - MGA - média geométrica anual

3 - MAA - média aritmética anual

Fonte: Cetesb (1994), "Relatório de Qualidade do Ar na Região Metropolitana de São Paulo e Cubatão - I993". 
dios agudos de poluição do ar, onde as concentrações dos poluentes ultrapassam os padrões primários. A Resolução no 3 do Conama estabeleceu critérios para os episódios agudos de poluição do ar, com a determinação de níveis de atenção, alerta e emergência, em ordem crescente de gravidade, que são assim definidos, para os principais poluentes, e estão apresentados na Tabela 3 .

Com base nos valores mensurados das concentrações dos poluentes relacionados na Tabela 3, a Cetesb divulga diariamente o Índice de Qualidade do Ar, desde 1981. Esse índice foi baseado no PSI-Pollutant Standard Index, desenvolvido pela EPA, e dá valores adimensionais para a qualidade do ar.

Esse índice classifica a qualidade do ar em seis categorias:

- Boa (0 - 50): quando as concentrações de todos os poluentes estão abaixo de $50 \%$ de seus padrões de qualidade;

- Regular (51 - 100): quando a concentração de pelo menos um dos poluentes atinge o seu padrão de qualidade;

- Inadequada (101 - 199): quando a con- centração de pelo menos um dos poluentes está entre o seu padrão de qualidade e os níveis de atenção;

- Má(200 - 299): quando a concentração de pelo menos um dos poluentes está entre os seus níveis de atenção e de alerta;

- Péssima (300 - 399): quando a concentração de pelo menos um dos poluentes está entre os seus níveis de alerta e de emergência;

- Crítica (maior que 400): quando a concentração de pelo menos um dos poluentes está acima do seu nível de emergência.

\section{EFEITOS DA POLUIÇÃO DO AR SOBRE A SAÚDE DOS HABITANTES DA CIDADE DE SÃO PAULO}

Há mais de uma década, o Laboratório de Poluição Atmosférica Experimental (LPAE), criado junto ao Departamento de Patologia da Faculdade de Medicina da

TABELA 3

Critérios para episódios agudos de poluição do ar

\begin{tabular}{lccc}
\hline & & Níveis & \\
\hline Parâmetros & Atenção & Alerta & Emergência \\
\hline $\begin{array}{l}\text { Partículas totais em suspensão } \\
(\mu \mathrm{g} / \mathrm{m} 3)-24 \mathrm{~h}\end{array}$ & 375 & 625 & 875 \\
\hline $\begin{array}{l}\text { Dióxido de enxofre } \\
(\mu \mathrm{g} / \mathrm{m} 3)-24 \mathrm{~h}\end{array}$ & 800 & 1.600 & 2.100 \\
\hline $\begin{array}{l}\mathrm{SO} \mathrm{O}_{2} \times \mathrm{PTS} \\
\left(\mu \mathrm{g} / \mathrm{m}^{3}\right)\left(\mu \mathrm{g} / \mathrm{m}^{3}\right)-24 \mathrm{~h}\end{array}$ & 65.000 & 261.000 & 403.000 \\
\hline $\begin{array}{l}\text { Monóxido de carbono } \\
(\mathrm{ppm})-8 \mathrm{~h}\end{array}$ & 15 & 30 & 1.000 \\
\hline $\begin{array}{l}\text { Ozônio } \\
\left(\mu \mathrm{g} / \mathrm{m}^{3}\right)-1 \mathrm{~h}\end{array}$ & 400 & 800 & 500 \\
\hline $\begin{array}{l}\text { Fumaça } \\
\left(\mu \mathrm{g} / \mathrm{m}^{3}\right)-24 \mathrm{~h}\end{array}$ & 250 & 420 & 500 \\
\hline $\begin{array}{l}\text { Partículas inaláveis } \\
\left(\mu \mathrm{g} / \mathrm{m}^{3}\right)-24 \mathrm{~h}\end{array}$ & 250 & 420 & 3.000 \\
\hline $\begin{array}{l}\text { Dióxido de nitrogênio } \\
\left(\mu \mathrm{g} / \mathrm{m}^{3}\right)-1 \mathrm{~h}\end{array}$ & 1.130 & 2.260 & \\
\hline
\end{tabular}

Fonte: Cetesb (1994), "Relatório de Qualidade do Ar na Região Metropolitana de São Paulo e Cubatão - I993". 
Universidade de São Paulo (FMUSP), iniciou estudos sobre a toxicidade dos produtos da combustão de combustíveis fósseis, derivados do petróleo, e de combustíveis originados de biomassa (álcool). Os resultados mostraram que os produtos derivados da queima dos combustíveis fósseis são mais tóxicos do que os gerados pela queima de biomassa.

Entretanto, a poluição do ar de uma cidade como São Paulo é resultado de uma mistura de gases e partículas em suspensão associada a características muito peculiares de temperatura, umidade e pressão que dificilmente poderiam ser recriadas em uma câmara de intoxicação. Por isso, o LPAEFMUSP resolveu redimensionar os clássicos estudos toxicológicos utilizando a própria cidade de São Paulo como câmara de intoxicação. Ratos de uma mesma ninhada foram divididos aleatoriamente e alocados em dois grupos. Um desses grupos foi colocado na região central da cidade, na torre da Igreja do Paissandu. O outro grupo foi levado para Atibaia, cidade com níveis de poluição muito inferiores aos registrados na região metropolitana de São Paulo. Os ratos que foram expostos à poluição da cidade de São Paulo apresentaram alterações nas características do muco produzido pelas células do epitélio respiratório, que se tornou mais espesso e de difícil remoção pelos cílios. Como resultado dessa e de outras alterações do sistema respiratório esse grupo apresentou mais casos de mortes de ratos por infecções respiratórias quando comparado com o grupo controle.

Com o estabelecimento de uma base fisiopatológica dos efeitos da poluição do ar, o LPAE-FMUSP passou a objetivar estimativas dos efeitos da poluição sobre a saúde dos habitantes da cidade de São Paulo. Os estudos observacionais foram a opção adotada e, dentre eles, os estudos ecológicos de séries temporais. Esse tipo de estudo apresenta algumas vantagens:

- permite analisar as variações nos níveis de poluentes e suas correlações com as variações observadas em indicadores de mortalidade e/ou morbidade ao longo de um período de tempo, em uma mesma ci- dade. Com isso, uma série de vieses comuns nos estudos que comparam múltiplos grupos podem ser evitados;

- os dados utilizados são secundários, tendo sido coletados para outras finalidades. Na cidade de São Paulo existem 14 estações de monitoramento da Cetesb que medem continuamente os níveis dos cinco principais poluentes do ar $\left(\mathrm{PM}_{10}, \mathrm{SO}_{2}, \mathrm{CO}\right.$, $\mathrm{NO}_{2}$ e ozônio). O Programa de Aprimoramento de Informações de Mortalidade (Proaim), do serviço funerário da Prefeitura de São Paulo, coleta e analisa todos os atestados de óbito de moradores da cidade, checando o seu preenchimento e contatando os médicos responsáveis nos casos de dúvidas. Esse cuidado faz com que as informações sobre mortalidade liberadas por esse órgão tenham excelente qualidade. O Data-SUS é o órgão de processamento de dados do Sistema Único de Saúde que faz o registro das internações hospitalares nos hospitais conveniados;

- e mais barato do que os estudos de coorte, outro tipo de estudo epidemiológico aplicado em epidemiologia ambiental.

Com esses estudos realizados na cidade de São Paulo chegamos a algumas conclusões importantes:

- crianças, adolescentes e idosos são as faixas etárias que se mostraram mais suscetíveis aos efeitos dos poluentes do ar;

- mortes fetais estão positivamente associadas às concentrações de poluentes do ar; - aumentos na poluição do ar promovem aumentos nas consultas de pronto-socorro e nas internações por doenças respiratórias e cardiovasculares;

- há um aumento na mortalidade respiratória para crianças e pessoas com mais de 65 anos devido a aumentos nos poluentes do ar; - os efeitos da poluição do ar são maiores nas regiões da cidade que apresentam piores indicadores socioeconômicos;

- não parece haver um nível de poluição que seja inócuo para a saúde dos habitantes da cidade.

Essas conclusões são verdadeiras e atuais mesmo em um cenário onde os níveis dos principais poluentes têm decrescido ao longo dos últimos anos. Entretanto, essa 
queda na concentração média dos poluentes do ar, que é decorrente, principalmente, da renovação da frota, pode se tornar temporária já que a frota de carros em São Paulo continua a crescer.

\section{PERSPECTIVAS FUTURAS E PROPOSTAS MITIGADORAS}

O problema da poluição do ar na cidade de São Paulo e seus efeitos sobre a saúde demanda medidas sérias e mudanças profundas nas políticas públicas adotadas até o presente momento. Estudos têm estimado que reduções nos níveis dos poluentes poderão diminuir os casos de mortes decorrentes da poluição do ar em grandes cidades do mundo. Essa é uma conclusão óbvia e que sempre foi clara para todos aqueles que se dedicam a estudar este sério problema de saúde pública.

No caso específico da cidade de São Paulo, mudar o cenário atual significa desacelerar a política de privilégios para o transporte individual e dedicar empenho pessoal e financeiro na implementação de um sistema de transporte público moderno, limpo e eficiente, que consiga interligar as diversas regiões da cidade de forma rápida e barata.

Nos últimos anos investiu-se uma grande soma de recursos públicos para construção de avenidas e viadutos e muito pouco foi feito para resolver o problema do transporte público na cidade.

Um sistema interligado de transporte sobre trilhos que contemple o aumento da malha ferroviária, tanto do metrô quanto da rede de trens urbanos, somado a um novo sistema de trólebus, mais ágil que os dois anteriores, poderá mudar o conceito atual de transporte público.

Uma frota de ônibus com veículos novos, com motores que queimem mais eficientemente o combustível e que apresentem mecanismos de redução de emissão de poluentes, além da utilização de combustíveis menos tóxicos, como o álcool e o gás natural.

Além disso, um controle rigoroso dos veículos que circulam pela cidade já tarda em muito. Vistorias periódicas de controle de emissão de poluentes e obrigatoriedade de instalação de catalisadores em todos os carros são medidas essenciais para melhorar a qualidade do ar.

Afastar os caminhões que usam a cidade como ponto de interligação entre diferentes rodovias e controlar a fumaça emitida por aqueles que trafegam por toda a região urbana são outros procedimentos que podem contribuir para a redução da poluição atmosférica.

A implementação de todas essas medidas e de outras que possam ser aventadas com o objetivo de diminuir a poluição do ar terá um custo. Porém, custos maiores, tanto financeiro quanto social, têm as doenças e mortes que ocorrem devido aos agentes tóxicos liberados no ar da cidade. Estudo do Banco Mundial que utilizou dados do LPAE-USP, entre outros institutos de pesquisa, estima em 15 milhões de dólares o custo anual com doenças relacionadas à poluição do ar. Somando-se a este valor os anos de atividade perdidos por aquelas pessoas que vêm a falecer a conta atinge valores assombrosos.

Resolver o problema da poluição do ar demanda disposição da autoridade pública em priorizar a saúde e coragem para enfrentar todos os elos da cadeia geradora de poluição, desde o dono da indústria de automóveis até o proprietário do veículo.

\section{BIBLIOGRAFIA}

ANDRÉ, P. A.; BRAGA, A. L. F.; CONCEIÇÃO, G. M. S.; LIN, C. A.; PEREIRA, L. A. A.; EL KOURY-MIRAGLIA, S. G.; BHÖM, G. M. "Environmental Epidemiology Applied to Urban Atmosferic Pollution - A Contribution from the Laboratory of Experimental Air Pollution (LEAP)", in Cad. Saúde Pública, 16(3), 2000, pp. 619-28.

BASCOM, R.; BROMBERG, P. A.; COSTA, D. A.; DEVLIN, R.; DOCKERY, D. W.; FRAMPTON, M. W.; LAMBERT, W.; SAMET, 
J. M.; SPEIZER, F. E.; UTELL, M. "Health Effects of Outdoor Pollution”, in Am. J. Respir. Crit. Care. Med. 153, 1996, pp. 3-50. BOBAK, M.; LEON, D. A. "Air Pollution and Infant Mortality in the Czech Republic, 1986-88", in Lancet340, 1992, pp. 1.010-4. BOBAK, M.; LEON, D. A. "The Effect of Air Pollution on Infant Mortality Appears Specific for Respiratory Causes in the Postneonatal Period", in Epidemiology 10, 1999, pp. 666-70.

BÖHM, G. M.; MASSAD, E.; SALDIVA, P. H. N.; GOUVEIA, M. A.; PASQUALUCCI, C. A. G.; CARDOSO, L. M. N.; CALDEIRA, M. P. R.; CALHEIROS, D. "Comparative Toxicity of Alcohol and Gasoline Fueled Automobile Exhaust Fumes", in A. W. Hayes, R. C. Scenell, T. S. Miya (eds.), Developments in the Science and Practice of Toxicology. Amsterdam, Elsevier Science, 1983, pp. 479-82.

BRAGA, A. L. F.; CONCEIÇÃO, G. M. S.; PEREIRA, L. A. A.; KISHI, H. S.; PEREIRA, J. C. R.; ANDRADE, M. F.; GONC̦ALVES, F. L. T.; SALDIVA, P. H. N.; LATORRE, M. R. D. 0. “Air Pollution and Pediatric Respiratory Hospital Admissions in São Paulo, Brazil", in J. Environ. Med. 1, 1999, pp. 95-102.

BRAGA, A. L. F.; SALDIVA, P. H. N. "Poluição e Saúde”, in J. Pneumol. S10-S16, 2001.

BRAGA, A. L. F.; SALDIVA, P. H. N.; PEREIRA, L. A. A.; MENEZES, J. J. C.; CONCEIÇ̃̃O, G. M. S.; LIN, C. A.; ZANOBETTI, A.; SCHWARTZ, J.; DOCKERY, D. W. "Health Effects of Air Pollution Exposure on Children and Adolescents in São Paulo, Brazil", in Pediatr. Pulmonol. 31, 2001, pp. 106-13.

BRAGA, A. L. F.; ZANOBETTI, A.; SCHWARTZ, J. “Do Respiratory Epidemics Confound the Association Between Air Pollution and Daily Deaths?", in Eur. Respir. J. 16(4), 2000, pp. 723-8.

DEJMEK, J.; SELEVAN, S. G.; BENES, I.; SOLANSK`Y, I.; SRÁM, R. J. "Fetal Growth and Maternal Exposure to Particulate Matter During Pregnancy", in Environ. Health Perspect. 107, 1999, pp. 475-80.

DOCKERY, D. W.; POPE, C. A. III. "Acute Respiratory Effects of Particulate Air Pollution", in Annu. Rev. Public. Health 15, 1994, pp. 107-32.

DOCKERY, D. W.; POPE, C. A. III; XU, X.; SPENGLER, J. D.; WARE, J. H.; FAY M. E.; FERRIS, B. G. Jr.; SPEIZER, F. E. "The Association between Air Pollution and Mortality in Six US Cities", in N. Eng. J. Med. 329, 1993, pp. 1753-9. LIN, C. A.; MARTINS, M. A.; FARHAT, S. C.; POPE, C. A. III; CONCEIÇÃO, G. M.; ANASTACIO, V. M.; HATANAKA, M.; ANDRADE, W. C.; HAMAUE, W. R.; BÖHM, G. M.; SALDIVA, P. H. N. "Air Pollution and Respiratory Illness of Children in São Paulo, Brazil", in Paediatr. Perinat. Epidemiol. 13, 1999, pp. $475-88$.

LOOMIS, D.; CASTILLEJOS, M.; GOLD, D. R.; MCDONNELL, W.; BORJA-ABURTO, V. H. “Air Pollution and Infant Mortality in Mexico City", in Epidemiology 10, 1999, pp. 118-23.

MIRAGLIA, S. G. E. K.; CONCEIÇÃO, G. M. S.; SALDIVA, P. H. N.; STRAMBI, 0. “Analysis of the Impact of Fuel Consumption on Mortality Rates in São Paulo", in L. Sucharov and G. Bidini (eds.), Urban Transport and the Environment for the 21 st Century III, Southampton, UK, Computational Mechanics Publication, 1997, pp. 435-44. PEREIRA, L. A. A.; LOOMIS, D.; CONCEIÇÃO, G. M. S.; BRAGA, A. L. F.; ARCAS, R. M.; KISHI, H.; SINGER, J. M.; BÖHM, G. M.; SALDIVA, P. H. N. "Association between Air Pollution and Intrauterine Mortality in São Paulo, Brazil", in Environ. Health Perspect. 106, 1998, pp. 325-9.

POPE, C. A. III. "Respiratory Hospital Admissions Associated with PM 10 Pollution in Utah Salt Lake, and Cache Valleys", in Arch. Environ. Health 46, 1991, pp. 90-7.

POPE, C. A. III; DOCKERY, D. W. "Acute Health Effects of PM ${ }_{10}$ Pollution on Symptomatic and Asymptomatic Children", in Am. Rev. Respir. Dis. 145, 1992, pp. 1.123-8.

SALDIVA, P. H. N.; KING, M.; DELMONTE, V. L. C.; MACCHIONE, M.; PARADA, M. A. C.; DALIBERTO, M. L.; SAKAI, R. S.; CRIADO, P. M. P.; SILVEIRA, P. L. P.; ZIN, W. A.; BÖHM, G. M. "Respiratory Alterations Due to Urban Air Pollution: an Experimental Study in Rats", in Environ. Res. 57, 1992, pp. 19-33.

SALDIVA, P. H. N.; LICHTENFELS, A. J. F. C.; PAIVA, P. S. 0.; BARONE, I. A.; MARTINS, M. A.; MASSAD, E.; PEREIRA, J. C. R.; XAVIER, V. P.; SINGER, J. M.; BÖHM, G. M. "Association between Air Pollution and Mortality Due to Respiratory Diseases in Children in São Paulo, Brazil: a Preliminary Report", in Environ. Res. 65, 1994, pp. 218-25. SALDIVA, P. H. N.; POPE C. A. III; SCHWARTZ, J.; DOCKERY, D. W.; LICHTENFELS, A. J. F. C.; SALGE, J. M.; BARONE, I.; BÖHM, G. M. "Air Pollution and Mortality in Elderly People: a Time-series Study in São Paulo, Brazil”, in Arch. Environ. Health 50, 1995, pp. 159-63.

SCHWARTZ, J.; DOCKERY, D. W. "Increased Mortality in Philadelphia Associated with Daily Air Pollution Concentrations", in Am. Rev. Respir. Disease 145, 1992, pp. 600-4.

TIMONEN, L. K.; PEKKANEN, J. "Air Pollution and Respiratory Health Among Children with Asthmatic or Cough Symptoms", in Am. J. Respir. Crit. Care. Med. 156, 1997, pp. 546-52.

WOODRUFF, T. J.; GRILLO, J.; SCHOENDORF, C. "The Relationship between Selected Causes of Postneonatal Infant Mortality and Particulate Air Pollution in the United States", in Environ. Health Perspect. 105, 1997, pp. 608-12. 